\title{
A novel MIP gene mutation associated with autosomal dominant congenital cataracts in a Chinese family
}

Yibo Yu ${ }^{1,2+}$, Yinhui $\mathrm{Yu}^{1,2+}$, Peiqing Chen ${ }^{1}$, Jinyu Li ${ }^{1,2}$, Yanan Zhu ${ }^{1,2}$, Yi Zhai $^{1,2}$ and Ke Yao ${ }^{1,2^{*}}$

\begin{abstract}
Background: The major intrinsic protein gene (MIP), also known as MIP26 or AQPO, is a member of the water-transporting aquaporin family, which plays a critical role in the maintenance of lifelong lens transparency. To date, several mutations in MIP (OMIM 154050) have been linked to hereditary cataracts in humans. However, more pathogenic mutations remain to be identified. In this study, we describe a four-generation Chinese family with a nonsense mutation in MIP associated with an autosomal dominant congenital cataract (ADCC), thus expanding the mutational spectrum of this gene.
\end{abstract}

Methods: A large four-generation Chinese family affected with typical Y-suture cataracts combined with punctuate cortical opacities and 100 ethnically matched controls were recruited. Genomic DNA was extracted from peripheral blood leukocytes to analyze congenital cataract-related candidate genes. Effects of the sequence change on the structure and function of proteins were predicted by bioinformatics analysis.

Results: Direct sequencing of MIP in all affected members revealed a heterozygous nucleotide exchange c.337C > T predicting an arginine to a stop codon exchange (p.R113X). The substitution co-segregated well in all the affected individuals in the family and was not found in unaffected members or in the 100 unrelated healthy controls. Bioinformatics analysis predicted that the mutation affects the secondary structure and function of the MIP protein.

Conclusions: We identified a novel mutation of MIP (p.R113X) in a Chinese cataract family. This is the first nonsense mutation of MIP identified thus far. This novel mutation is also the first disease-causing mutation located in the loop $C$ domain of MIP. The results add to the list of mutations of the MIP linked to cataracts.

Keywords: Autosomal dominant congenital cataract, MIP, Y-suture cataract, Nonsense mutation

\section{Background}

Congenital cataract is the leading cause of visual impairment in children, and it is responsible for approximately $10 \%$ of irreversible childhood blindness worldwide, with a prevalence of 1 to 6 cases/10,000 live births [1,2]. It was reported that about $8.3-25 \%$ of congenital cataracts are inherited [3], with autosomal dominant transmission the most common mode of inheritance, although autosomal recessive and X-linked traits of inheritance exist [4]. Congenital cataracts may occur in an isolated fashion or in

\footnotetext{
* Correspondence: xlren@zju.edu.cn

${ }^{\dagger}$ Equal contributors

${ }^{1}$ Eye Center, Second Affiliated Hospital of Zhejiang University School of

Medicine, No.88 Jiefang Road, Hangzhou 310009, China

Full list of author information is available at the end of the article
}

association with other ocular dysmorphology, as well as systemic malformations [3].

Knowledge of the genetic background of congenital cataract has increased considerably during the past decennia. To date, more than 35 independent loci have been identified for nonsyndromic cataract, segregating most often as an autosomal dominant trait, of which 25 represent identified genes [3,5]. The number of mutations exceeds 100 [3,5]. Among the cataract mutations reported, about half involve crystallines, and a quarter involve connexins $[3,5,6]$. The remainder are divided among the genes for heat shock transcription factor-4 (HSF4), major intrinsic protein $(M I P)$, and beaded filament structural protein2 (BFSP2) $[3,5,6]$.
C Biomed Central (c) 2014 Yu et al.; licensee BioMed Central Ltd. This is an Open Access article distributed under the terms of the Creative Commons Attribution License (http://creativecommons.org/licenses/by/2.0), which permits unrestricted use, distribution, and reproduction in any medium, provided the original work is properly cited. The Creative Commons Public Domain Dedication waiver (http://creativecommons.org/publicdomain/zero/1.0/) applies to the data made available in this article, unless otherwise stated. 
MIP, a member of the water-transporting aquaporin family, is the most abundant junctional membrane protein in lens fiber cells, constituting more than $60 \%$ of the total membrane protein content of these cells $[7,8]$.It plays a critical role in conferring rapid movements of water across cell membranes and controlling the water content of cells $[9,10]$. To date, several mutations in human MIP, including missense and frameshift mutations, have been reported to induce inherited cataracts.

This study aimed to identify the molecular defects in autosomal dominant congenital cataracts in a large Chinese family. And a novel nonsense mutation in MIP that cosegregated with the disease was identified to be responsible for the congenital cataracts.

\section{Methods}

\section{Family enrollment and genomic DNA preparation}

A four-generation Chinese family from a remote mountain region of Guizhou province with autosomal dominant congenital cataract (ADCC) was recruited from the Eye Center of the 2nd Affiliated Hospital, Medical College of Zhejiang University, Hangzhou, China. This study was approved by the Zhejiang University Institutional Review Board, and the study protocol followed the principles of the Declaration of Helsinki. After appropriate informed consent was obtained from the participants, all family members underwent detailed ophthalmological examinations, including visual acuity, slit lamp, and fundus examinations with dilated pupils.

Genomic DNA was extracted from the peripheral blood leukocytes using the Simgen Blood DNA mini kit (Simgen, Hangzhou, China) for PCR amplification. A total of 100 ethnically matched subjects withouta family history of congenital cataracts were recruited as controls.

\section{Mutation screening}

We used the functional candidate gene analysis approach. Ten genes most frequently involved in autosomal dominant cataract were analyzed: $C R Y A A, C R Y A B, C R Y B A 3 / A 1$, CRYBB1, CRYBB2, CRYGC, CRYGD, GJA3, GJA8, and $M I P$. All coding exons and intron-exon boundaries of the candidate genes were amplified by PCR using previously published primer sequences $[11,12]$. The cycling conditions for PCR were as follows: $95^{\circ} \mathrm{C}$ preactivation for 5 min, 10 cycles of touchdown PCR with $1^{\circ} \mathrm{C}$ down per cycle from $60^{\circ} \mathrm{C}$ to $50^{\circ} \mathrm{C}$, followed by 25 cycles with denaturation at $95^{\circ} \mathrm{C}$ for $25 \mathrm{~s}$, annealing at $55^{\circ} \mathrm{C}$ for $25 \mathrm{~s}$ and extension at $72^{\circ} \mathrm{C}$ for $40 \mathrm{~s}$, then finally extension at $72^{\circ} \mathrm{C}$ for $10 \mathrm{~min}$. The thermal cycling was performed under suitable conditions using a C1000 TM 48-well thermal cycler (Bio-Rad, Hercules, CA). PCR products were isolated by electrophoresis on $1.5 \%$ agarose gels and sequenced using the BigDye Terminator Cycle sequencing kit V3.1 (Applied Biosystems, Foster City, CA) on an Applied
Biosystems PRISM 3730 Sequence Analyzer, according to the manufacturer's directions. Sequencing results were analyzed using Chromas 1.62 and compared with sequences from the NCBI GenBank database.

\section{Bioinformatics analysis}

To predict the effect of this nonsense mutation on the protein, we used the online SWISS-MODEL and DEEP VIEW/SWISS-Pdb tool to analyze both the mutant and wild-type version of the structure of the MIP protein. For hydropathy analysis, we used Compute $\mathrm{pI} / \mathrm{MW}$ to predict the isoelectric point (pI) and the molecular weight $(\mathrm{MW})$ of the wild-type and mutant protein. Furthermore, online Mutation Taster software was used to distinguish between functionally neutral and deleterious mutations.

\section{Results}

\section{Clinical evaluation}

We identified a four-generation Chinese family (8 affected and 8 unaffected) with a clear diagnosis of ADCC (Figure 1). The proband was a 26-year-old female who had underwent bilateral cataract surgery in our hospital in March and May 2013 to obtain a driving license. To obtain more information about the cataract phenotype and to collect the blood samples, we went to their place of residence and identified the identical phenotype within all affected members. The phenotype was a typical bilateral Y-sutural cataract, combined with punctuate cortical opacities (Figure 2). The older affected members (II:4,III:9,III:17) were aged from 23 to 55 years and the younger ones (IV:12,IV:13,IV:14,IV:19) were aged from 3 to 10 years. None of the affected patients whose visual acuity ranged from 0.6 to 1.0 complained of significant visual deterioration, and they were also unaware of their cataracts until the examinations. As they had not underwent ocular examinations before, we were unable to determine the exact age of onset of the cataract. However, we may speculate that all the affected individuals showed early onset of cataract because the youngest member (IV:19) already had a mild cataract. Other than the cataracts, there were no other ocular or systemic abnormalities or symptoms.

\section{Mutation screening}

We identified a heterozygous change, $\mathrm{C}>\mathrm{T}$, at position 337 (c. $337 \mathrm{C}>\mathrm{T}$ ) of the MIP gene, leading to the replacement of a wild-type arginine with a stop codon at the 113th amino acid position (p.R113X) (Figure 3). It co-segregated well with all affected individuals and was not found in unaffected family members or in the 100 unrelated normal controls. This strongly suggests that the R113X mutation may act as a disease-causing mutation rather than a benign polymorphism in linkage disequilibrium with the disease. 


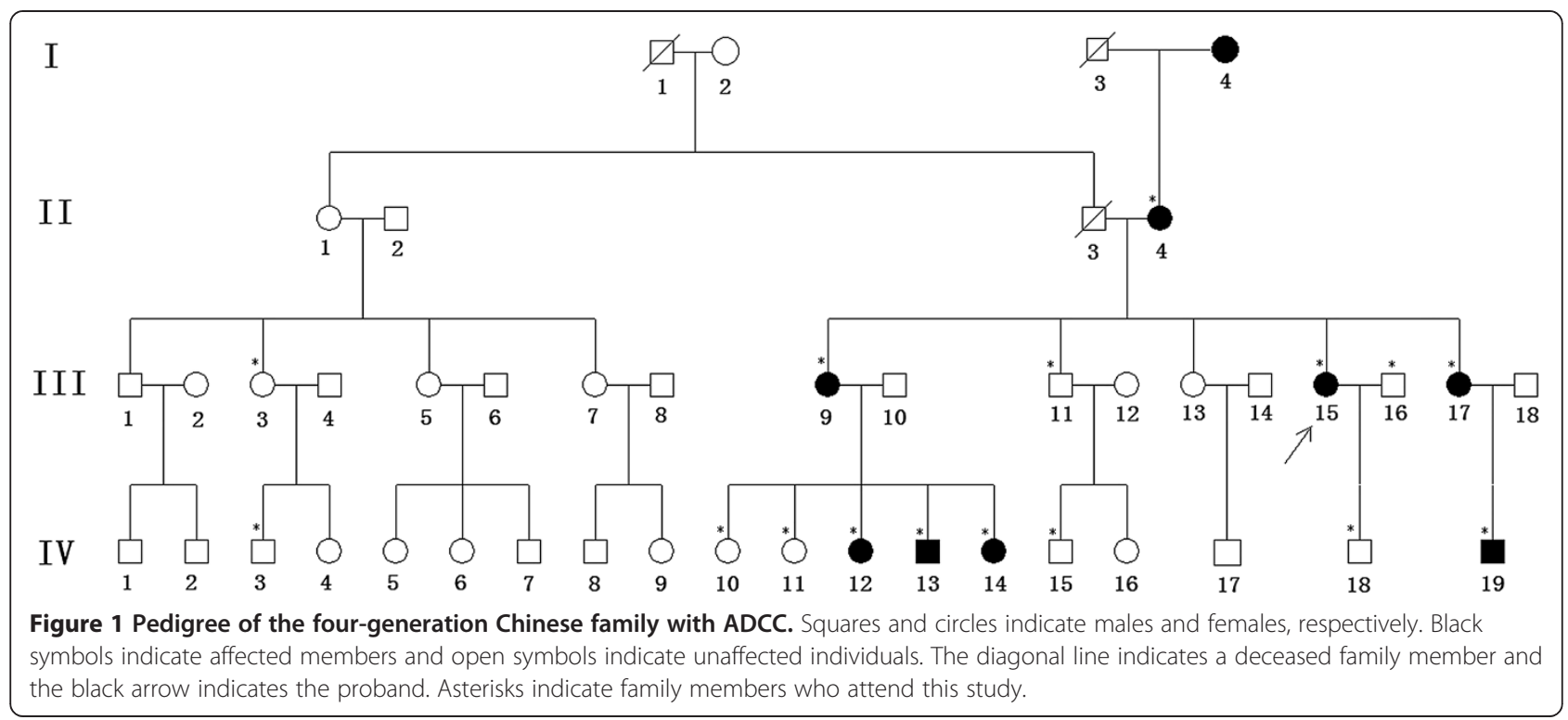

\section{Bioinformatics analysis}

The automated homology protein of human MIP was modeled in three dimensions by the Swiss-Model and DEEP VIEW/SWISS-Pdb tool. The results clearly showed that the shortened protein contained only 113 amino acids rather than the normal 263 (Figure 4). This gave rise to a severely truncated protein that lacks important functional domains on the C-terminal region. The theoretical $\mathrm{pI}$ of mutant MIP was increased to 9.18 compared to the wildtype $\mathrm{pI}$ of 8.62 . The MW of the mutant (11956 Da) was significantly reduced compared to the MW of the wildtype MIP (28121 Da), as predicted by Compute pI/MW. Results obtained with the online bioinformatics software Mutation Taster showed that the mutation was predicted to be "probably damaging."

\section{Discussion}

As the most abundant membrane protein within lens fiber cells, MIP facilitates the movement of water into and across lens fiber cells. Besides functioning as a water channel, it may also act as an adhesion molecule, compacting highly ordered fiber cells and minimizing extracellular space and light scattering to maintain the lens transparency [13]. To date, 10 mutations of MIP have been associated with congenital cataract (c.97C $>\mathrm{T} \quad$ [p.R33C] [12], c.401A > G [p.E134G] [14], c.413C > G [p.T138R] [14], c.530A $>$ G [p.Y177C] [15], c.559C > T [p.R187C] [16], c.698G > A [p.R233K] [17], c.2 T > C [p.Met1?] [18], c.494G > A [p.G165D] [19], IVS-1G > A [p.V203fs] [20], and c.638delG [p.G213VfsX46] [21]). As we all know, the dominantly inherited mutations are mainly missense

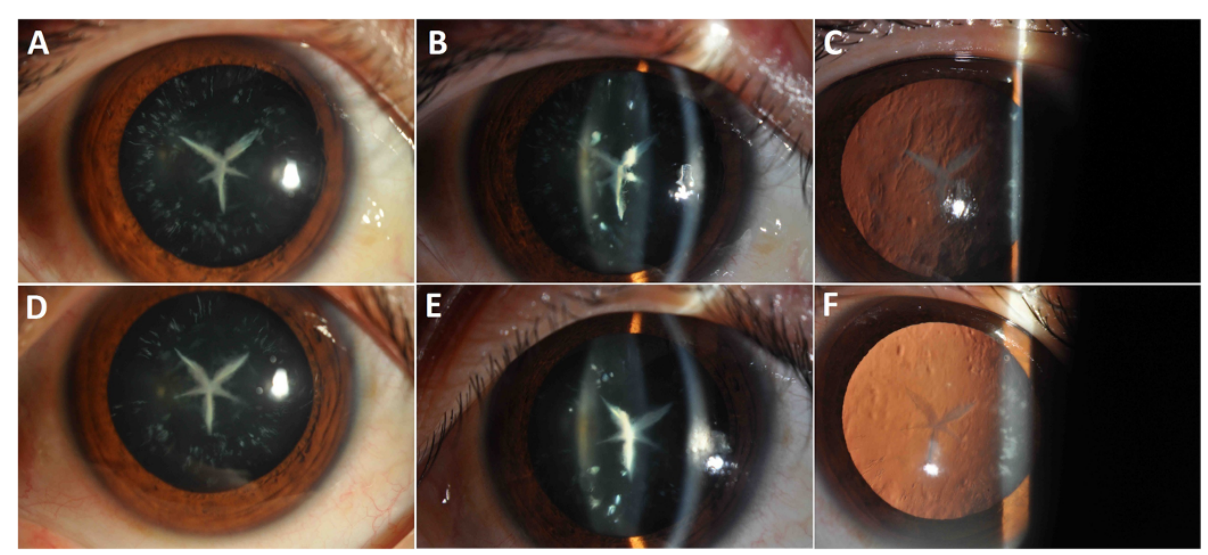

Figure 2 Slit lamp photographs (diffuse illumination, silt lamp and retro-illumination) of the proband (III:15) which shows bilateral Y-suture cataract combined with punctuate cortical opacities, A, B, C denotes the right eye and D, E, F denotes the left eye, respectively. 


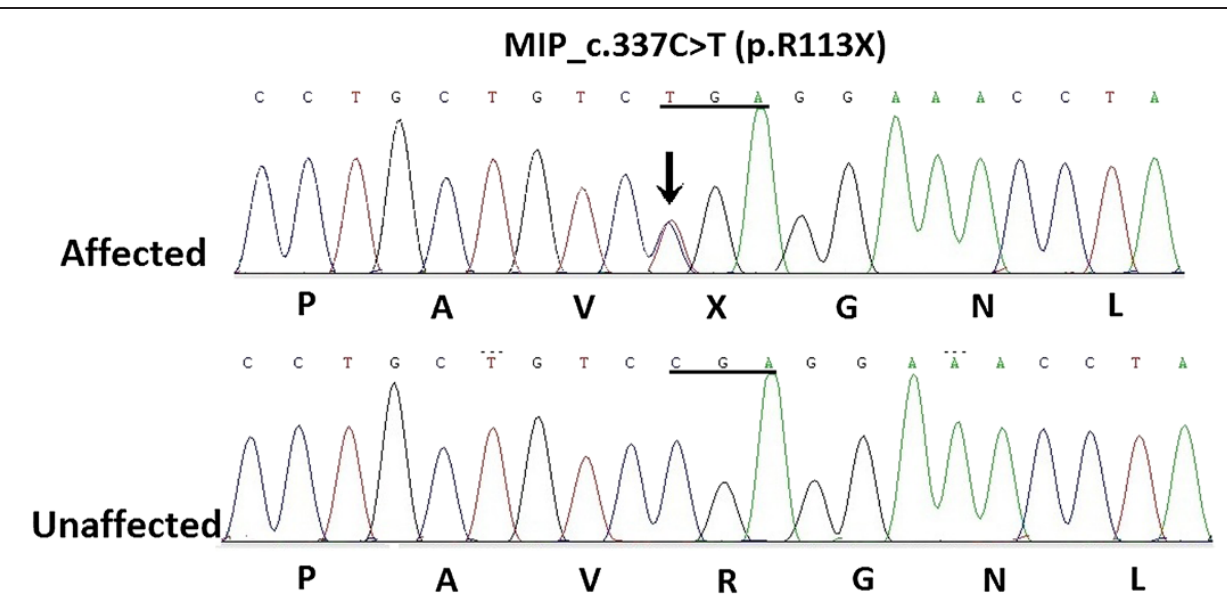

Figure 3 DNA sequence chromatograms of the proband (III:15) shows a heterozygous C > T nucleotide change in exon 1 of MIP (black zrrow) which altered the Arg to a stop codon (TGA) and an unaffected individual (III:12) shows CGA at the same codon 113.

mutations that lead to amino acid substitutions, other examples include nonsense or frame shift mutations. And the severity of the cataract may be determined by anatomic location, size, density, and progression of the opacity. In general, the more posteriorly located and dense an opacity, the greater the impact on visual function $[2,22]$. The cataract family we reported was associated with a nonsense mutation (c.337C $>\mathrm{T}$ [p. $\mathrm{R} 113 \mathrm{X}]$ ) which produced a severely truncated protein. While this mutation produced an identical phenotype of $Y$ suture cataract combined with fine punctate opacities in the cortex which did not involve the posterior part of the lens. This would well explain why there was no complaint of distinctly decreased visual acuity from all patients.
The phenotypes of cataracts are significantly different among MIP mutation families, pointing to the presence of extensive clinical heterogeneity of hereditary cataracts. We compared the phenotype of our family with one affected member of a cataract family reported by Geyer et al. [21] in 2006 and found that the clinical features were very similar: Both manifested as fine punctate opacities in the cortex and Y suture. They reported a single nucleotide deletion, which caused a frameshift and premature stop codon that truncated 6 amino acids from the C-terminus of MIP. More interestingly, when we analyzed the phenotypes of other reported families, we found that 3 of 10 examples (30\%) had opacities involving Y sutures $[14,18,21]$. The way in which the lens suture forms may explain this finding. As is well known,
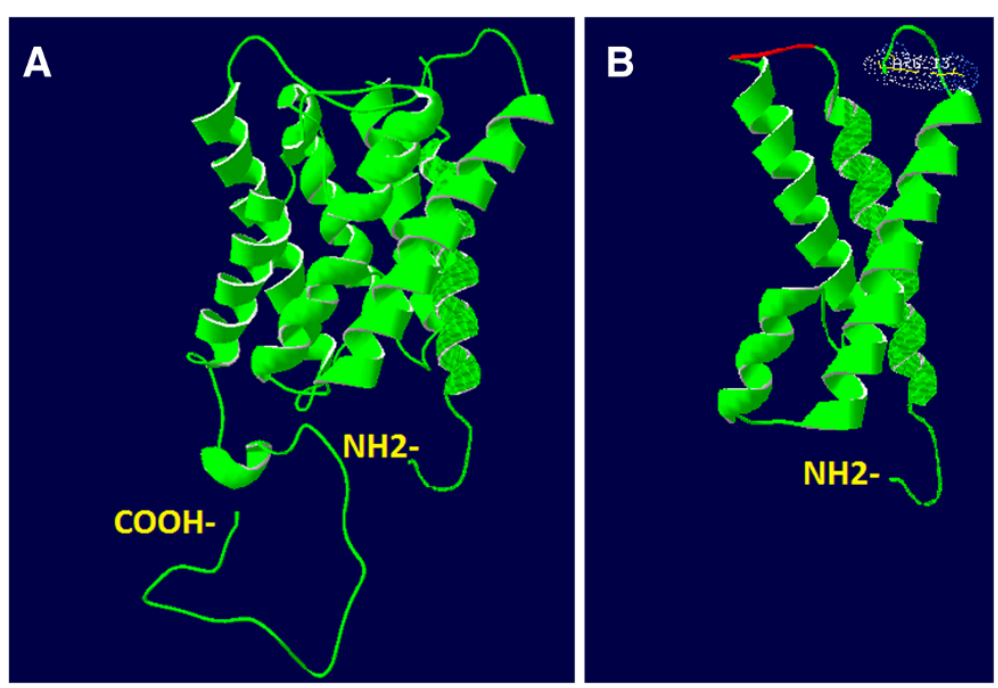

Figure 4 The structural model of the MIP protein. A: A structural homology model of the wild-type human MIP protein is displayed. B: A structural alteration of the mutant MIP is displayed. 151 amino acids are truncated from the $\mathrm{COOH}$-terminus of MIP as a result of C. 337 C > T mutation. 
MIP is expressed as soon as the first primary fibers start filling the lens vesicle, and it continues to be expressed as the secondary fibers are differentiated from the equatorial epithelial cells [23]. When the terminal ends of the secondary fibers overlap with one another, lens sutures form [24]. Deletion of the MIP gene in mice led to a lack of suture formation $[25,26]$. The important role that MIP plays in suture formation is consistent with the phenotype observed in MIP mutation families.

Four mutations, E134G [14], T138R [14], G165 D [19], and c.638delG [21], have been functionally characterized in vitro. The E134G, T138R [23], and G165D mutations may result in loss of water permeability due to failure in trafficking of proteins to the plasma membrane. The 638G deletion [27] may cause the mutant protein to be retained in the endoplasmic reticulum and induce cellular cytotoxicity. The nonsense mutation identified in this study encodes a premature stop codon, resulting in a shortened protein with 151 amino acids. This produces a severely truncated protein and deletes important functional domains on the $\mathrm{C}$-terminal domain, including loop C, D, E, transmembrane domains (H4-H6), and hemipores HE (Figure 5). The shortened protein may alter voltage dependence and calmodulin-binding properties of the protein. Our finding is quite similar to the Mip mutation identified in KFRS4/Kyo cataract rats by Watanabe et al. [28]. In their study, they found a 5-bp insertion in the Mip gene that generated a frameshift and a premature stop codon at amino acid position 127, which produced a truncated protein that lacks 136 amino acids in the C-terminal region. No MIP-positive band in the eye extracts from the mutant rats was detectable by immune-blot, and a lack of MIP-specific immune-fluorescence in eye sections from the mutants also indicated the absence of normal protein. These results suggest that the kfrs 4 mutation conveys a loss-offunction, which leads to functional inactivation though the degradation of Mip mRNA by nonsense-mediated mRNA decay (NMD). The NMD pathway is an effective mRNA surveillance system that detects and degrades mRNA containing premature termination codons (PTC) and protects cells from potentially deleterious effects of

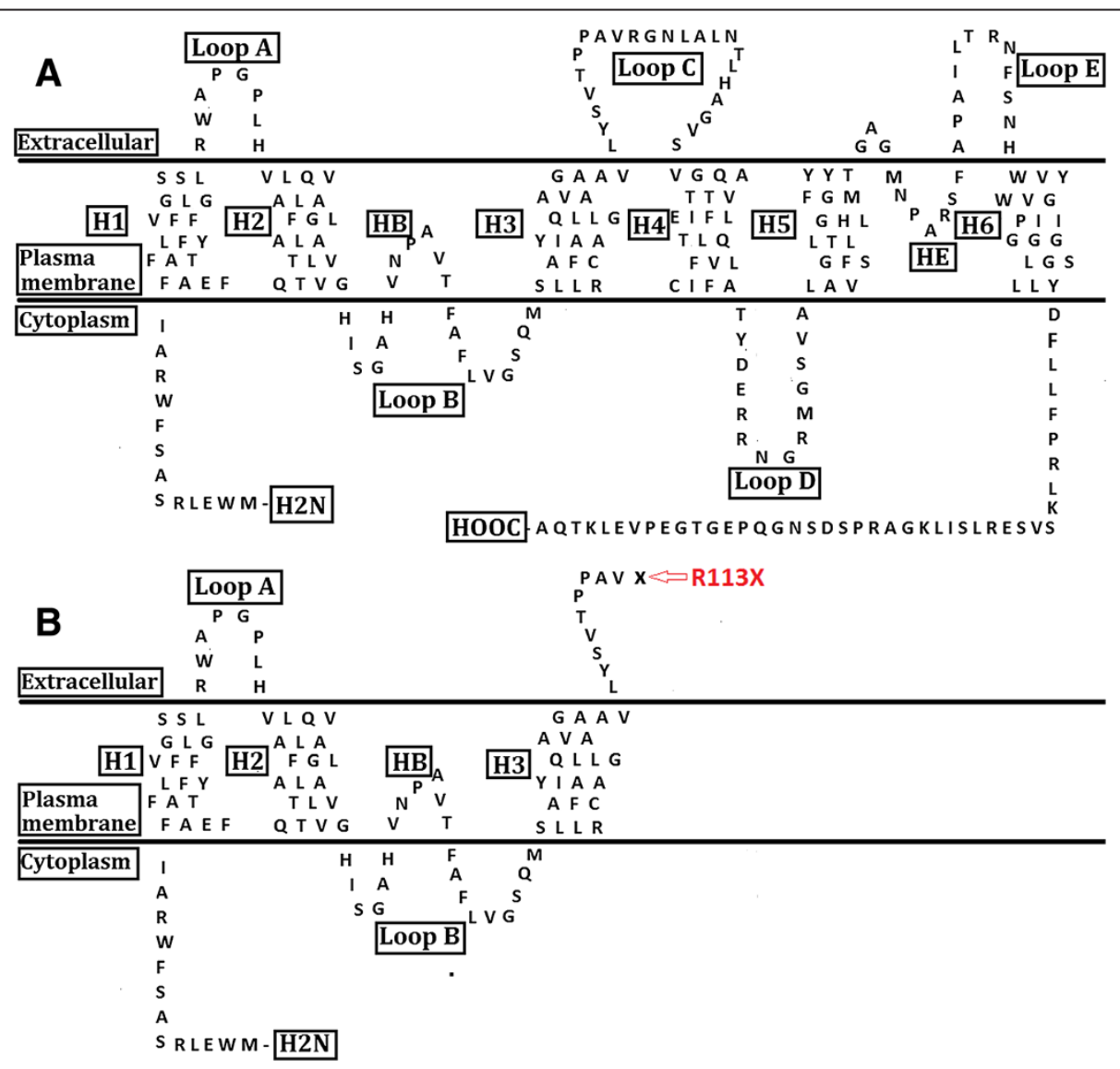

Figure $\mathbf{5}$ The schematic diagram of the protein. A: The schematic diagram of the predicted structure of MIP protein (modified from Watanabe $\mathrm{K}$ et al. [28]) encoded by the wild-type. B: The mutated schematic illustrates premature truncation of the protein. The locations of six transmembrane helices ( $\mathrm{H} 1, \mathrm{H} 2, \mathrm{H} 3, \mathrm{H4}, \mathrm{H5}$, and H6), two hemichannels ( $\mathrm{HB}$ and HE), the extracellular (Loop A, C, and E) and intracellular (Loop B and D) loops and two asparagine-proline-alanine (NPA) motif are indicated. 
truncated proteins [29-32]. As the site and resultant truncation of the mutation identified in the present study are quite similar to the KFRS4 rat mutation, we may speculate that the mutant transcripts of this nonsense mutation may escape the NMD pathway and that PTC-mRNAs are translated to abnormal proteins, with potential dominant-negative effects on cells. Further study is needed to provide insights into the molecular consequence of this nonsense mutation.

\section{Conclusion}

In this study, we have described the first nonsense mutation in MIP causing autosomal dominant congenital cataracts in a large Chinese family. It is also the first mutation located in the loop C domain of MIP. Our data expand the spectrum of MIP mutations and validate the extensive clinical and genetic heterogeneity of congenital cataract. None of the affected members in the family complained of significant visual deterioration in their daily life. The identification of this mutation may enable proper genetic diagnostics and counseling in both young and elderly patients.

\section{Competing interests}

The authors declare that they have no competing interest.

\section{Authors' contributions}

$Y Y$ and KY obtained the funding, designed the research and revised the manuscript. YY carried out the molecular genetic studies, participated in the sequence alignment, analyzed most of the data, and drafted the manuscript. $J \mathrm{~L}$ and $Y Z$ carried out sample collection and helped prepare the laboratory work. $P C$ and $Y Z$ participated in the design of the research, help the acquisition of the clinical data and revision of the manuscript. All authors have read and approved the final manuscript.

\section{Acknowledgments}

We are grate thankful to all the family members for participating in this study. This research was supported by the Key Program of National Natural Science Foundation of China (No.81130018), Program of National Natural Science Foundation of China (No.81371001), National "Twelfth Five-Year" Plan for Science \& Technology Support of China (No.2012BAI08B01) Zhejiang Key Innovation Team Project of China (2009R50039), Zhejiang Key Laboratory Fund of China (2011E10006) and Project of National Clinical Key Discipline of Chinese Ministry of Health.

\section{Author details}

${ }^{1}$ Eye Center, Second Affiliated Hospital of Zhejiang University School of Medicine, No.88 Jiefang Road, Hangzhou 310009, China. ${ }^{2}$ Zhejiang Provincial Key Lab of Ophthalmology, Hangzhou, China.

Received: 23 October 2013 Accepted: 7 January 2014

Published: 9 January 2014

\section{References}

1. Apple DJ, Ram J, Foster A, Peng Q: Elimination of cataract blindness: a global perspective entering the new millenium. Surv Ophthalmol 2000, 45(Suppl 1):S1-S196.

2. Francis PJ, Berry V, Bhattacharya SS, Moore AT: The genetics of childhood cataract. J Med Genet 2000, 37:481-488.

3. Hejtmancik JF: Congenital cataracts and their molecular genetics. Semin Cell Dev Biol 2008, 19:134-149.

4. Vanita J, Singh D: Genetic and segregation analysis of congenital cataract in the indian population. Clin Genet 1999, 56:389-393.
5. Shiels A, Bennett TM, Hejtmancik JF: Cat-map: putting cataract on the map. Mol Vis 2010, 16:2007-2015.

6. Shiels A, Hejtmancik JF: Genetic origins of cataract. Arch Ophthalmol 2008, 125:165-173.

7. Bloemendal H, Zweers A, Vermorken F, Dunia I, Benedetti EL: The plasma membranes of eye lens fibres. Biochemical and structural characterization. Cell Differ 1972, 1:91-106.

8. Gorin MB, Yancey SB, Cline J, Revel JP, Horwitz J: The major intrinsic protein $(M I P)$ of the bovine lens fiber membrane: characterization and structure based on cDNA cloning. Cell 1984, 39:49-59.

9. Borgnia M, Nielsen S, Engel A, Agre P: Cellular and molecular biology of the aquaporin water channels. Annu Rev Biochem 1999, 68:425-458,

10. Shiels A, Bassnett S, Varadaraj K, Mathias R, Al-Ghoul K, Kuszak J, Donoviel D, Lilleberg S, Friedrich G, Zambrowicz B: Optical dysfunction of the crystalline lens in aquaporin-0-deficient mice. Physiol Genomics 2001, 7:179-186.

11. Li J, Wang Q, Fu Q, Zhu Y, Zhai Y, Yu Y, Zhang K, Yao K: A novel connexin 50 gene (gap junction protein, alpha 8) mutation associated with congenital nuclear and zonular pulverulent cataract. Mol Vis 2013, 19:767-774.

12. Gu F, Zhai H, Li D, Zhao L, Li C, Huang S, Ma X: A novel mutation in major intrinsic protein of the lens gene ( MIP ) underlies autosomal dominant cataract in a Chinese family. Mol Vis 2007, 13:1651-1656.

13. Engel A, Fujiyoshi $Y$, Gonen T, Walz T: Junction-forming aquaporins. Curr Opin Struct Biol 2008, 18:229-235.

14. Berry $\mathrm{V}$, Francis $\mathrm{P}$, Kaushal $\mathrm{S}$, Moore A, Bhattacharya S: Missense mutations in MIP underlie autosomal dominant polymorphic and lamellar cataracts linked to 12q. Nat Genet 2000, 25:15-17.

15. Yang G, Zhang G, Wu Q, Zhao J: A novel mutation in the MIP gene is associated with autosomal dominant congenital nuclear cataract in a Chinese family. Mol Vis 2011, 17:1320-1323.

16. Wang KJ, Li SS, Yun B, Ma WX, Jiang TG, Zhu SQ: A novel mutation in MIP associated with congenital nuclear cataract in a Chinese family. Mol Vis 2011, 17:70-77.

17. Lin H, Hejtmancik JF, Qi Y: A substitution of arginine to lysine at the $\mathrm{COOH}$-terminus of MIP caused a different binocular phenotype in a congenital cataract family. Mol Vis 2007, 13:1822-1827.

18. Xiao X, Li W, Wang P, Li L, Li S, Jia X, Sun W, Guo X, Zhang Q: Cerulean cataract mapped to $12 q 13$ and associated with a novel initiation codon mutation in MIP. Mol Vis 2011, 17:2049-2055.

19. Senthil Kumar G, Kyle JW, Minogue PJ, Dinesh Kumar K, Vasantha K, Berthoud VM, Beyer EC, Santhiya ST: An MIP/AQP0 mutation with impaired trafficking and function underlies an autosomal dominant congenital lamellar cataract. Exp Eye Res 2013, 110:136-141.

20. Jiang J, Jin C, Wang W, Tang X, Shentu X, Wu R, Wang Y, Xia K, Yao K: Identification of a novel splice-site mutation in MIP in a Chinese congenital cataract family. Mol Vis 2009, 15:38-44.

21. Geyer DD, Spence MA, Johannes M, Flodman P, Clancy KP, Berry R, Sparkes RS, Jonsen MD, Isenberg SJ, Bateman JB: Novel single-base deletional mutation in major intrinsic protein (MIP) in autosomal dominant cataract. Am J Ophthalmol 2006, 141:761-763.

22. Parks $M$, Johnson D, Reed G: Long term visual results and complications in children with aphakia: a function of cataract type. Ophthalmology 1993, 100:826-841.

23. Francis $P$, Chung JJ, Yasui M, Berry V, Moore A, Wyatt MK, Wistow G, Bhattacharya SS, Agre P: Functional impairment of lens aquaporin in two families with dominantly inherited cataracts. Hum Mol Genet 2000, 9:2329-2334.

24. Kuszak JR, Zoltoski RK, Tiedemann CE: Development of lens sutures. Int J Dev Biol 2004, 48:889-902.

25. Al-Ghoul KJ, Kirk T, Kuszak AJ, Zoltoski RK, Shiels A, Kuszak JR: Lens structure in MIP-deficient mice. Anat Rec A Discov Mol Cell Evol Biol 2003, 273:714-730.

26. Varadaraj K, Kumari SS, Mathias RT: Functional expression of aquaporins in embryonic, postnatal, and adult mouse lenses. Dev Dyn 2007, 236:1319-1328.

27. Varadaraj K, Kumari SS, Patil R, Wax MB, Mathias RT: Functional characterization of a human aquaporin 0 mutation that leads to a congenital dominant lens cataract. Exp Eye Res 2008, 87:9-21.

28. Watanabe K, Wada K, Ohashi T, Okubo S, Takekuma K, Hashizume R, Hayashi J, Serikawa T, Kuramoto T, Kikkawa Y: A 5-bp insertion in mip causes recessive congenital cataract in KFRS4/Kyo Rats. PLoS One 2012, 7:e50737.

29. Hentze MW, Kulozik AE: A perfect message: RNA surveillance and nonsense-mediated decay. Cell 1999, 96:307-310. 
30. Maquat LE, Carmichael GG: Quality control of mRNA function. Cell 2001, 104:173-176.

31. Khajavi M, Inoue K, Lupski JR: Nonsense-mediated mRNA decay modulates clinical outcome of genetic disease. Eur J Hum Genet 2006, 14:1074-1081.

32. Baker KE, Parker R: Nonsense-mediated Mrna decay: terminating erroneous gene expression. Curr Opin Cell Biol 2004, 16:293-299.

doi:10.1186/1471-2350-15-6

Cite this article as: Yu et al.: A novel MIP gene mutation associated with autosomal dominant congenital cataracts in a Chinese family. BMC Medical Genetics 2014 15:6.

\section{Submit your next manuscript to BioMed Central and take full advantage of:}

- Convenient online submission

- Thorough peer review

- No space constraints or color figure charges

- Immediate publication on acceptance

- Inclusion in PubMed, CAS, Scopus and Google Scholar

- Research which is freely available for redistribution 